\title{
A INJUSTIÇA AMBIENTAL DAS EXTERNALIDADES NEGATIVAS DAS MONOCULTURAS PARA COMMODITIES AGRÍCOLAS DE EXPORTAÇÃO NO BRASIL
}

\author{
Cristiane Derani ${ }^{1}$ \\ Mariana Caroline Scholz ${ }^{2}$
}

\begin{abstract}
RESUMO: O crescimento do agronegócio baseado em monoculturas no Brasil se fortaleceu nas últimas décadas devido a incentivos fiscais e financiamentos bancários, de modo que a produção agrícola tem grande importância para a economia brasileira pelas atividades voltadas à produção de commodities para exportação. Entretanto, o avanço de atividades monocultoras extensivas ocasiona diversos impactos ambientais e sociais, externalidades negativas, que são absorvidos pela sociedade gerando extensa vulnerabilidade e injustiça ambiental. $\mathrm{O}$ presente artigo tem por finalidade apontar a grande injustiça ambiental causada pelas externalidades negativas absorvidas pela sociedade das monoculturas no Brasil.
\end{abstract}

Palavras-chave: Justiça ambiental; Agronegócio; Monoculturas; Externalidades negativas.

\section{THE ENVIRONMENTAL INJUSTICE OF THE NEGATIVE EXTERNALITIES OF MONOCULTURES FOR EXPORT AGRICULTURAL COMMODITIES IN BRAZIL}

\begin{abstract}
The growth of agribusiness based on monocultures in Brazil has been strengthened in the last decades due to fiscal incentives and bank financing, so that agricultural production is of great importance to the Brazilian economy due to activities aimed at the production of commodities for export. However, the advance of extensive monoculture activities causes a number of environmental and social impacts, negative externalities, which are absorbed by society, generating widespread vulnerability and environmental injustice. The present article aims to point out the great environmental injustice caused by the negative externalities absorbed by the monoculture society in Brazil.
\end{abstract}

Keywords: Environmental justice; Agribusiness; Monocultures; Negative externalities.

\footnotetext{
1 Professora da Universidade Federal de Santa Catarina, Brasil, onde ensina Direito Internacional Público, Direito Econômico Internacional e Direito Ambiental Internacional. Coordenadora de Pesquisa do grupo de pesquisa sobre "Estudos Avançados em Economia e Meio Ambiente em Direito Internacional" (EMAE), bem como Pesquisadora da Agência Nacional de Pesquisas (CNPq). Formou-se em Direito pela Universidade Estadual de São Paulo (1988), escreveu sua tese de doutorado em J.W. Goethe Universitaet, Frankfurt a.M. (1991-1993), e recebeu um Ph.D. em Direito Econômico na USP (1996), onde atuou como Professora Associada (1997-2004). Realizou estudos de pós-doutorado na Ecole des Hautes Etudes en Sciences Sociales (EHESS), na França, sobre a Privatização de Serviços Públicos e Desenvolvimento Sustentável (1999). Professora visitante da Maison de Sciences de l'Homme (2005), bem como professora visitante do J.W. Goethe Universitaet (2005). Pós-Doutorado na universidade de Cambridge, Reino Unido.

${ }^{2}$ Doutoranda em Direito pela Universidade Federal de Santa Catarina (UFSC). Bolsista do CNPq. Mestre em Direito pela Universidade Federal de Santa Catarina (UFSC). Membro do Grupo de Pesquisa EMAE/UFSC. Bolsista do CNPq. Trabalha com foco em Direito Internacional Público, Economia e Meio Ambiente no Direito Internacional e Direito Ambiental Constitucional
} 


\section{INTRODUÇÃO}

O Brasil é conhecido pela exploração de recursos naturais desde a colonização em produtos como pau-brasil, café, açúcar e borracha. Esse processo de exploração foi impulsionado com a modernização industrial e tecnológica que possibilitaram a expansão da exploração dos recursos naturais.

Não é segredo que o processo produtivo da agricultura se intensificou em maquinário, insumos e tecnologia de sementes, bem como se introduziu cultivos para o mercado externo (commodities). Hoje a agricultura é vista como um ramo de produção não diferente de uma indústria, na qual o Brasil é um expoente em produção e exportação de produtos agrícolas.

Neste sentido, se intensificaram as monoculturas e se fomentou a agroindústria por um conjunto de políticas institucionais e econômicas. A agricultura se tornou agronegócio, capaz de competir externamente e gerar riqueza. Vislumbrou-se o potencial de produção de áreas como cerrado e Amazônia, abriu-se possibilidade ao comércio exterior de gêneros agrícolas e o setor progrediu de forma competitiva. $\mathrm{O}$ agronegócio direciona sua matriz produtiva para atender ao mercado externo, antes era o trigo e o açúcar, atualmente é a soja.

Diretamente desse modo de produção de commodities para exportação derivam externalidades negativas, que envolvem desmatamento, monoculturas, organismos geneticamente modificados, utilização de insumos químicos (agrotóxicos, fertilizantes químicos). Os impactos ambientais e sociais de tais processos são extensos e precisam ser considerados na continuidade da sociedade e dos seus modos de produção.

Por isso, o objetivo deste trabalho é analisar as externalidades negativas dos processos produtivos agrícolas absorvidos pela sociedade, sob a ótica teórica da Justiça ambiental. De modo a atingir esse objetivo, o trabalho se realiza uma pesquisa bibliográfica e documental, de forma qualitativa.

O artigo é dividido em três tópicos, primeiramente é abordado sobre o agronegócio de commodities, com destaque para a soja. Em seguida se apontam as externalidades negativas das monoculturas da soja. E, por fim, se aborda a Justiça ambiental e o agronegócio, analisando as externalidades negativas. 


\section{O AGRONEGÓCIO DE COMMODITIES - A SOJA NO BRASIL}

O setor agropecuário lidera a economia brasileira, em 2016 o faturamento da agropecuária foi de $\mathrm{R} \$ 523,62$ bilhões, as lavouras tiveram um valor bruto da produção de R \$ 340,6 bilhões, e a pecuária, $\mathrm{R} \$ 183$ bilhões. Isso representou 23\% no Produto Interno Bruto (PIB) e 48\% das exportações totais do país, o que significa uma movimentação de US\$ 72,5 bilhões em vendas externas. (CNA, 2016)

Para esse resultado o Ministério da Agricultura, Pecuária e Abastecimento (MAPA), juntamente com outros órgãos, atua no sentido de subsidiar custeios e viabilizar políticas de estímulo ao crescimento e distribuição de linhas de crédito. O montante dos recursos disponibilizados para o crédito rural e as condições de financiamento ao produtor rural totalizou R\$ 183,8 bilhões $^{3}$. (BRASIL, 2016)

Para compreender melhor o agronegócio no Brasil é preciso observar os dados atualizados das produções agrícolas. Segundo o relatório de Produção Agrícola de 2015, realizado pelo Instituto Brasileiro de Geografia e Estatística (IBGE, 2016), foram verificadas 63 culturas, e destas somente três culturas concentram $61,6 \%$ do valor da produção brasileira: soja, milho e cana de açúcar. Essas três produções somam 58,2 milhões de hectares utilizados pela agricultura (75,8\% da participação total de 76,8 milhões de hectares), e R \$ 163,8 bilhões no valor da produção (61,7\% da participação total $)^{4}$.

Das três produções é a soja a mais utilizada para a exportação. Enquanto em 2015 foram produzidas 97,5 milhões de toneladas, só foi consumido pelo mercado interno 42,5 milhões de toneladas, o que significa que 55 milhões de toneladas (56\%) foram destinadas à exportação (CONAB, 2016, p. 132). Enquanto para o milho o consumo é estimado em 56,5 milhões de toneladas $(66 \%)$ e 28,8 milhões para a exportação (CONAB, 2016, p.122). E a cana de açúcar, utilizada para o etanol (56\%) e açúcar (43\%) exporta somente $6 \%$ do etanol produzido e $70 \%$ do açúcar, cerca de 2 milhões de toneladas. (CONAB, 2016, p. 23)

\footnotetext{
${ }^{3}$ Desses recursos, no valor de R $\$ 183,8$ bilhões, R $\$ 149,8$ bilhões serão destinados para financiamentos de custeio e de comercialização, sendo $\mathrm{R} \$ 115,6$ bilhões de recursos controlados, com taxas de juros inferiores às de mercado, e R \$ 34,2 bilhões de recursos livres. Para os financiamentos de investimento serão destinados R\$34,0 bilhões, abrangendo os programas de investimento com recursos do BNDES e do Banco do Brasil, no valor de R $\$ 18,0$ bilhões, sendo que os recursos oriundos das demais fontes e programas somam o montante de R\$15,9 bilhões. (BRASIL, 2016)

${ }^{4} \mathrm{O}$ milho e a soja impulsionam a agricultura batendo recordes de produção: a soja com a média de 97,5 milhões de toneladas (12,3\% maior que em 2014) e uso de 32,2 milhões de hectares; e o milho 85,3 milhões de toneladas $(6,8 \%$ maior que em 2014) em 15,8 milhões de hectares; já a cana de açúcar 748,6 milhões de toneladas $(3,1 \%$ maior que 2014) produzidas em 10,2 milhões de hectares. (IBGE, 2016, p. 3-7)
} 
Diante desses dados é possível concluir que a soja é a produção foco para a exportação no Brasil, cerca de 27 milhões de toneladas a mais que o milho e 50 toneladas a mais que a cana de açúcar. Bem como é a produção que mais exige hectares, com o dobro de área do milho e três vezes a área da cana de açúcar. É por estes motivos que o estudo aqui se volta para a produção de soja no Brasil, o produto mais significativo em termos de produção, utilização de terra e exportação.

É amplamente divulgado que a soja é a lavoura que mais cresce no Brasil, em um resgate histórico pode-se observar a evolução da plantação de soja pela figura abaixo:

Figura 1 - Mapa comparativo Produção de Soja no Brasil por toneladas 1977/2002.

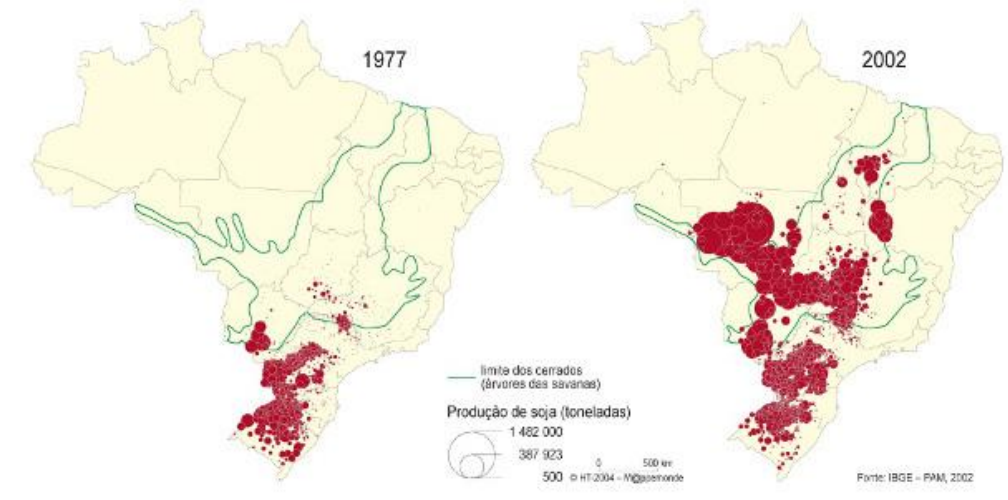

Fonte: IBGE, 2002.

Somente a partir de 1960, impulsionada pela política de subsídios ao trigo visando autossuficiência, que a soja se estabeleceu como cultura economicamente importante e revolucionou a agricultura, primeiro no estado do Rio Grande do Sul. O sucesso do cultivo se deu porque as cultivares importadas dos Estados Unidos adaptaram-se muito bem às condições de clima e solo do Sul do Brasil, assim começou uma nova era da agricultura gaúcha - o binômio soja (verão) x trigo (inverno) - que trouxe uma série de inovações técnicas e enriqueceu o Estado (EMBRAPA, 2017). E assim, a produção só cresceu com apoio do mercado internacional, por isso o Brasil intensificou o plantio como pode-se ver na figura sobre a produção em 2015:

Figura 2 - Mapa Produção de Soja no Brasil por toneladas em 2015, com destaque para os munícipios mais produtivos. 


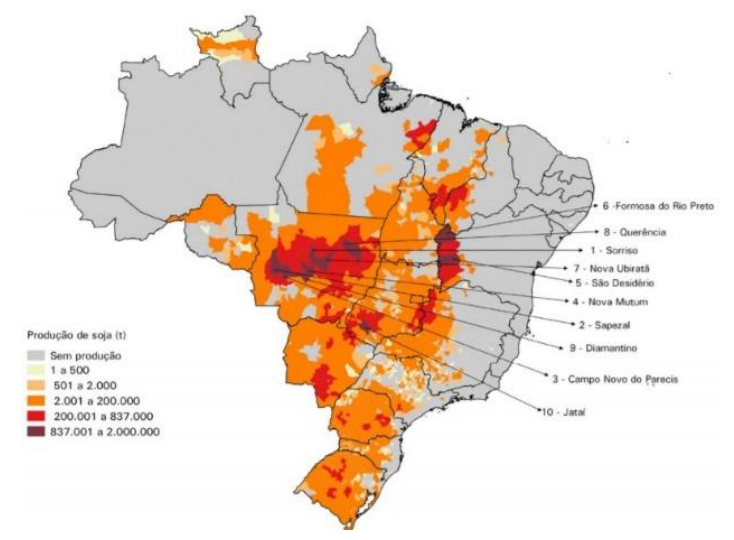

Fonte: IBGE, 2016.

Essas duas imagens demonstram como a expansão da soja representa um aumento considerável das áreas de plantio, e mais ainda, que a plantação da soja é itinerante ${ }^{5}$.

De forma a se ter os dados ainda mais atualizados, em fevereiro de 2017 o IBGE publicou o relatório de indicadores com as estatísticas da produção agrícola. Veja-se que a estimativa para 2017 são 224,2 milhões de toneladas de cereais e oleaginosas, superior à obtida em 2016 (184,0 milhões de toneladas). (IBGE, 2017)

Para essa quantidade indica-se o uso de 60,3 milhões de hectares, apresentando acréscimo de 5,7\% que 2016 (57,1 milhões de hectares). A produção de soja a cada ano bate recordes, para 2017 segue em crescimento, com a produção estimada em 108404791 toneladas, que reflete um crescimento de $13,2 \%$ em relação a $2016^{6}$. (IBGE, 2017, p. 7)

De acordo com os dados atualizados em junho de 2017 da EMBRAPA (2017) o Brasil é o segundo maior produtor de soja no mundo, com a produção de 113,923 milhões de toneladas e área plantada de 33,890 milhões de hectares ${ }^{7}$, perdendo somente para os Estados Unidos com produção de 117,208 milhões de toneladas e área plantada de 33,482 milhões de hectares.

De toda essa produção, estima-se que o consumo interno de soja seja de 47,281 milhões de toneladas, o que significa que 66,642 milhões de toneladas (58\%) são utilizadas para exportação, movimentando U\$ 25,4 bilhões em commodities. (EMBRAPA, 2017).

\footnotetext{
${ }^{5}$ Cabe o destaque para os dados do mapa do estado do Rio Grande do Sul, um dos primeiros estados a plantar soja, que cada vez mais diminui a plantação de tal produto enquanto o plantio cresce em outras regiões.

${ }^{6}$ O Mato Grosso estimou a produção 29905165 toneladas, um aumento de 13,8\% frente ao período anterior. No Paraná se estimou uma produção de 18809432 toneladas no estado, incremento de 11,8\% em relação a 2016. Na Região Nordeste deve haver um aumento de $84,6 \%$ no volume produzido. (IBGE, 2017, p. 7)

${ }^{7}$ Os maiores estados produtores são: Mato Grosso (Produção: 30,514 milhões de toneladas. Área plantada: 9,323 milhões de hectares); Paraná (Produção: 19,534 milhões de toneladas Área plantada: 5,250 milhões de hectares). Rio Grande do Sul (Produção: 18,714 milhões de toneladas. Área plantada: 5,570 milhões de hectares). (EMBRAPA, 2017)
} 
Segundo outro relatório emitido pelo Ministério da Agricultura, Pecuária e Abastecimento (MAPA) existe uma projeção de crescimento para a soja para 2015/26 que totaliza 129,2 milhões de toneladas, um acréscimo de no mínimo 35,1\% em relação à produção de 2015/16 (MAPA, 2016, p. 38). Neste relatório, existe a estimativa que a área de soja deve aumentar 10,0 milhões de hectares nos próximos 10 anos, chegando em 2026 a 43,2 milhões de hectares. É a lavoura que mais deve expandir a área na próxima década, um acréscimo de 30,2\% sobre a área de soja em 2015/16 ${ }^{8}$. O acréscimo de área é seguido pela cana-de-açúcar com cerca de 1,9 milhão de hectares adicionais. Demais lavouras devem ter pouca variação de área.

Esse número significativo de expansão direciona-se para expansão de fronteiras das lavouras, principalmente terras de pastagens naturais ${ }^{9}$ (MAPA, 2017, p. 39). E estima-se que expansão deve ocorrer em áreas de grande potencial produtivo, como as áreas de cerrados compreendidas na região que atualmente é chamada de Matopiba, por compreender terras situadas nos estados de Maranhão, Tocantins, Piauí e Bahia. (MAPA, 2017, p. 41)

Apesar do aumento significativo na produção de soja em 35,1\%, ou seja, 129.181 milhões de toneladas, o consumo interno só deverá atingir 53,5 milhões de toneladas, $22 \%$ de aumento. Enquanto a exportação deve aumentar para 78,053 milhões de toneladas, 41\% de aumento para a exportação de soja.

Diante de tais dados é possível observar como as monoculturas para commodities agrícolas de exportação no Brasil estão em plena expansão, em destaque a soja. E que o Brasil não espera avançar a produção para consumo interno, mas sim para exportação.

Assim, o agronegócio no Brasil é um fenômeno que ocorre no contexto da reprimarização da economia, da expansão da fronteira agrícola para a exportação de commodities. Isso também significa a afirmação do modelo da modernização agrícola conservadora e da monocultura químico-dependente, esse modelo gera uma série de problemas ambientais e sociais, como se verá a seguir.

\footnotetext{
${ }^{8}$ As projeções deste relatório indicam uma taxa média anual para os próximos dez anos de 2,7\%. Apesar de elevada, essa taxa está bem abaixo da taxa média observada nos últimos dez anos, que foi de 5,8\% ao ano. (MAPA, 2017) ${ }^{9}$ Pastagens naturais são as constituídas pelas áreas destinadas ao pastoreio do gado, sem terem sido formadas mediante plantio.
} 


\section{AS EXTERNALIDADES NEGATIVAS DAS MONOCULTURAS DE SOJA}

Como visto, a cultura de soja é o expoente do agronegócio brasileiro e sua continua expansão começa a chamar atenção para os efeitos dessa produção no meio ambiente, as chamadas externalidades. De forma geral, o conceito de externalidade refere-se aos efeitos das atividades de produção e consumo que não se refletem diretamente nos valores. O efeito das externalidades é difícil de ser mensurado pela complexidade que se verá nesse tópico.

Primeiramente, é preciso destacar que existem três formas diferentes de cultivo de soja, a orgânica, a convencional e a transgênica. Atualmente cabe ao produtor a escolha do sistema de produção a ser implementado.

A cultura orgânica utiliza sementes naturais, livres de modificação genética, também evita o uso de fertilizantes solúveis e pesticidas químicos nas operações, valoriza o uso de matéria orgânica para a agricultura ecologicamente equilibrada. A soja convencional é aquela que utiliza sementes livres de modificação genética, mas com grande utilização de fertilizantes e agrotóxicos para o controle de pragas e doenças, bem como utilização de maquinários no processo produtivo (SCHMITZ; KAMMER, 2006). Por último, a soja transgênica são organismos geneticamente modificados (OGM), produzidos principalmente para serem resistentes a herbicidas, insetos e até $\operatorname{secas}^{10}$.

Mas por que o destaque para os transgênicos sobre as externalidades da soja? Porque dentre as culturas brasileiras é na soja que se apresenta a maior concentração de sementes transgênicas utilizadas, pelas notícias de 2016 um total de 96,5\% do cultivo de soja é transgênico. Se a área plantada de soja em 2017 totaliza 33,890 milhões de hectares, 32,7 milhões de hectares utilizam soja transgênica ${ }^{11}$. (ARAÚJO, 2016)

E desse processo recente e intenso começam a aparecer impactos preocupantes para o meio ambiente. Ocorre um cultivo expressivo de sementes geneticamente modificadas introduzidas no

\footnotetext{
${ }^{10}$ É interessante destacar que, como explica Londres (2017) os transgênicos desenvolvidos para a soja não foram desenvolvidos para serem mais produtivos, mas sim para resistir a herbicidas e/ou para matar insetos. A maioria dos transgênicos cultivados possuem a característica de serem resistentes a herbicidas, se antes o agricultor precisava utilizar o agrotóxico (para matar matos) com cuidado para não danificar a própria lavoura, agora podem utilizar os produtos a vontade sem risco para a planta geneticamente modificada. Um segundo tipo de transgênico possuem no próprio código genético da planta toxinas inseticidas, ou seja, quando um inseto se alimenta da planta ele morre. E um terceiro tipo combinam as duas características, resistência a herbicidas e propriedades inseticidas na própria genética da planta.

${ }^{11}$ Mas isso é um processo extremamente recente, avalia-se que até 2002 somente $22,1 \%$ da soja plantada no Brasil era transgênica. Em 15 anos, de 2003 até 2017 houve a adesão massiva dos produtores brasileiros para os transgênicos. Isso só ocorreu após intensas disputas depois da autorização da Comissão Técnica Nacional de Biossegurança (CTNBio) do Ministério da Ciência e Tecnologia liberar o plantio de soja transgênica no país, da edição de diversas Medidas Provisórias e por último da Lei no 11.105/2005
} 
meio ambiente e, consequentemente, a quantidade de agrotóxicos aumentou também. Era de se esperar que a introdução das sementes transgênicas levasse à redução do consumo dos agrotóxicos, porém isso não aconteceu, pelo contrário, ao longo dos anos verificou-se aumento no uso dos mesmos.

Como se pode verificar pelos dados do Ministério do Meio Ambiente (BRASIL, 2017c), o Brasil é o maior consumidor de produtos agrotóxicos no mundo. Em dez anos, de 2002 até 2012 houve um aumento quase o triplo de quantidade, concomitantemente com o aumento do uso de OGM's (IBGE, 2015). Houve um aumento de 162,32\% entre 2000 a 2012. Segundo o Dossiê ABRASCO (CARNEIRO, et.al, 2015), o consumo de agrotóxicos em 2011 chegou a 850 milhões de litros, e 6,5 milhões de toneladas de fertilizantes. Desse volume, somente a soja utiliza $40 \%$ do volume total, seguida pelo milho com $10 \%$.

A expansão desmedida das monoculturas sobre os biomas em resposta à oportunidade conjuntural criada com o aumento da demanda externa por commodities agrícolas fez com que o Brasil assumisse nos últimos anos o nada honroso posto de maior consumidor mundial de agrotóxicos. (CARNEIRO, et.al, 2015, p. 32)

Assim, as monoculturas de soja apresentam alguns fatores preocupantes para a saúde humana e ambiental: a expansão e migração; os sistemas de monocultura; as sementes geneticamente modificadas e; o uso massivo de insumos químicos (fertilizantes e agrotóxicos). São esses fatores que geram as externalidades negativas que serão abordadas neste tópico.

\subsection{A EXPANSÃO E MIGRAÇÃO}

Um dos primeiros problemas que se levanta sobre a soja é a sua expansão. Como observado acima, estima-se um crescimento na produção e uso de 10,0 milhões de hectares nos próximos 10 anos, chegando a 43,2 milhões de hectares. Isso significa a uma pressão sobre as áreas atuais e abertura de novas áreas para a monocultura de soja, consequentemente desmatamento de florestas e savanas.

Uma coisa é clara pelas estimativas atuais, serão necessárias mais terras para plantar mais soja. Muitos produtores expandem a produção pelo plantio em antigas pastagens, ainda assim, a soja continua a pressionar as florestas - inclusive a Floresta Amazônica, a Mata Atlântica e a Floresta Seca Chiquitano -, bem como as paisagens mistas, as savanas e as pastagens naturais tais como o Cerrado, o Grande Chaco, os Pampas e pradarias. (WWF, 2014, p. 34) 
A expansão nas últimas décadas ocorreu pela conversão agrícola de vastas áreas de floresta e savanas, além das pastagens. Vislumbra-se um desmatamento progressivo com intensa fragmentação dos biomas naturais e o desaparecimento de diversas espécies (ISA, 2003). A conversão dos ecossistemas naturais em uso agrícola ${ }^{12}$ desencadeia efeitos extremamente nocivos como declínio da biodiversidade ${ }^{13}$, perda florestal, emissão de gases do efeito estufa, destruição dos ecossistemas e dos serviços ambientais que eles prestam, desde água limpa e solo saudável até a polinização e controle de pragas.

Como ressalta a organização World Wide Fund for Nature (WWF), conforme são destruídos ou degradados os ecossistemas “[...] perdemos muitos dos serviços ambientais dos quais dependemos". Existe também um impacto social, tais áreas abrigam muitas comunidades indígenas, às quais provê alimentos, abrigo, combustível, remédios e um meio de sustento. A expansão da soja implica na expulsão e remoção de comunidades indígenas e tradicionais das terras visadas, ocasionando intensos conflitos sociais. (WWF, 2014, p. 35)

O Cerrado, Mata Atlântica e Amazônia estão extremamente ameaçados pelo desmatamento causado pela soja, por meio da conversão direta e, em alguns casos, pela transferência da produção de gado para a fronteira florestal. Embora a utilização de terras de pastoreio para a cultura de soja seja positiva, isso contribui para a transferência da produção de gado para a floresta, um deslocamento indesejado da pecuária para as áreas florestadas mais periféricas ${ }^{14}$. (WWF, 2014, p. 39)

Simultaneamente, se observa o problema da migração da soja. Os estados tradicionalmente produtores, como o Rio Grade do Sul, Mato Grosso do Sul, São Paulo, Minas Gerais e Santa Catarina tenham suprido 54\% da produção total do Brasil em 1990, essa parcela caiu para 37\% em 1999. O cultivo da soja encontrou nesses estados a alta fertilidade natural do solo que necessitava, podendo crescer sem modificações ou grande aplicação de insumos químicos. A onda de crescimento e o deterioramento destas terras empurrou a produção para o norte, que com acesso a

\footnotetext{
${ }^{12}$ A área total da América do Sul dedicada ao cultivo da soja aumentou de 17 milhões de ha em 1990 para 46 milhões de ha em 2010. E isso ocorreu principalmente em terras que são resultado da conversão de ecossistemas naturais. (WWF, 2014)

${ }^{13}$ A biodiversidade está em declínio: de acordo com o Índice do Planeta Vivo, da Rede WWF, as populações de espécies de regiões tropicais diminuíram, em média, 60\% desde 1970. (WWF, 2014, p. 34)

${ }^{14}$ No mesmo sentido, o desenvolvimento da infraestrutura para a plantação de soja, com novas rodovias e portos, originalmente para melhorar a logística de transporte da soja e redução de custos, tem como efeito colateral a intensificação do desmatamento pelas estradas pavimentadas em si e pela facilidade da exploração de outros recursos naturais como a madeira. (WWF, 2014, p. 36)
} 
OMG's e insumos alcançou a savana do Cerrado, solos que anteriormente eram considerados pobres para uma cultura intensiva ${ }^{15}$.

Especificamente sobre o solo, estima-se que o ciclo de vida da produção de soja provoca erosão do solo em 8 toneladas anuais por hectare, ocorre a perda de matéria orgânica, compactação e acidificação do solo, sem falar na qualidade dos cursos de água (WWF, 2014, p 62). Este cenário explica os motivos de migração da soja para outras regiões e facilita a compreensão das externalidades negativas das culturas intensivas de soja, fundadas no desmatamento para expansão e na degradação pelo sistema de produção de monocultura ${ }^{16}$.

\subsection{AS MONOCULTURAS}

É o sistema de produção por monocultura, característico do agronegócio, o responsável pelo desequilíbrio ecológico nos diversos biomas. Quando se realiza o plantio de uma única variedade com alta taxa de produção, intensiva adubação, irrigação e pesticidas a repercussão não poderia deixar de ser perda de biomassa, redução da cobertura vegetal nativa (desmatamento), desequilíbrio dos ciclos biogeoquímicos (compactação e erosão do solo, assim como consumo excessivo de água e assoreamento de rios e nascentes), alterações climáticas e redução da biodiversidade ${ }^{17}$.

Os biomas e a biodiversidade são diretamente afetados. Os biomas estáveis pelos serviços e relações ecossistêmicas entram em colapso com a perda da vegetação, solo e água ${ }^{18}$ (MMA, 2017).

\footnotetext{
${ }^{15}$ A soja se deslocou para o cerrado e agora está se deslocando para a Amazônia legal, com crescimento de $10 \%$ em relação a 1998. Trata-se de uma redistribuição da produção, uma migração da produção de soja para a parte norte e a incorporação das terras vastas e baratas do cerrado na Bacia Amazônica. (WALKER et. al., 2017, p. 13)

Especificamente, essa produção amazônica e expansão para baixas latitudes só é possível por soja geneticamente modificada para o clima da região. (WWF, 2014, p. 21)

${ }^{16}$ Uma pesquisa no estado do Rio Grande do Sul, o primeiro a plantar soja, demonstrou que pelo menos seis mil hectares da zona rural estejam tomados pela areia, um fenômeno conhecido como arenização . Um pesquisador da UFRGS reconhece a relação entre a arenização e a concentração fundiária dos pampas, sobretudo pela cultura de soja. (GIOVANAZ, 2017). Essa arenização está localizada especialmente no sudoeste do estado, que criou efeitos negativos socioeconômicos para a população local: perda da qualidade de vida no campo, aumento da pobreza da região e êxodo rural são alguns dos efeitos . (GIOVANAZ, 2017)

Na região do entorno do Parque Nacional do Xingu, no Mato Grosso, os impactos ambientais causados pela sojicultura foram detectados pelo Instituto Socioambiental (ISA), apontando erosão, assoreamento nos principais rios que fazem parte do parque, e têm suas nascentes fora do parque.

${ }^{17}$ Como visto, as monoculturas são responsáveis pela perda do solo, ocasionando erosão e arenização. Isto ocorre, pois, um solo saudável necessita de matéria orgânica e nutrientes, que só são mantidas pela variedade biológica. Quando se tem uma monocultura as plantas retiram do solo todos os nutrientes e não existe renovação biológica. Em áreas sem rotação de cultura, a soja causa erosão do solo.

${ }^{18}$ Diante disso, a monocultura altera todo o meio na qual é inserida e causa ruptura do equilíbrio natural, desde animais até matéria orgânica, o que representa um problema sério de relações interdependentes. Espécies de plantas e animais desaparecem, ou se transformam em pragas, o controle químico vira necessidade e que por sua vez cria variedades resistentes aos mesmos. (ISA, 2003)
} 
O equilíbrio dos ecossistemas depende da diversidade biológica, na cadeia de interações das matérias e animais. Especialmente nas regiões tropicais ${ }^{19}$, em que a diversidade biológica é imensa, isso significa circuitos de matéria e energia mais complexos como um todo. (PORTOGONÇALVES , 2006, p. 255)

Qualquer alteração do cenário natural já reduz a diversidade biológica do ambiente, nos casos de monocultura o desequilíbrio é marcante. Desta forma, o plantio de uma modalidade de planta impede a diversidade genética da cultura, bem como favorece o aumento da população de patógenos e pragas de forma epidêmica que não encontram resistência natural e podem colocar em risco toda a cultura ${ }^{20}$. As monoculturas rompem os ciclos ambientais e possuem uma necessidade permanente de subsídios externos (fertilizantes e agrotóxicos) ${ }^{21}$, um ciclo vicioso. (SOARES, 2010).

Na questão social, a expansão dos monocultivos gera conflitos com os povos indígenas, comunidades quilombolas, ribeirinhas, colônias de pescadores, agricultores rurais e campesinos, além dos grupos ambientalistas que procuram defender os ecossistemas ameaçados. Esse tipo de cultivo afeta todas as populações que dependem da agroecologia e dos ciclos naturais, gera violência na disputa por territórios, bem como nas denúncias de degradações dos ecossistemas. (ISA, 2003)

O grande argumento a favor das monoculturas, e todos esses inconvenientes, é a alegação de maior produtividade. Mas esse argumento é facilmente contestável uma vez que a maior produtividade pode ser associada ao incremento na utilização de fertilizantes ${ }^{22}$. Assim, as externalidades negativas estão se mostrando superiores à produção por monoculturas ${ }^{23}$.

\footnotetext{
${ }^{19}$ Segundo estudo apresentado por Maria Leonor Lopes Assad, nas condições do clima tropical são necessárias centenas de anos para a formação de um centímetro de solo bem estruturado. Maria Leonor explica que "os processos erosivos que ocorrem nos solos são tanto mais intensos quanto maior for a ruptura entre o equilíbrio existente no ambiente, em particular entre solos e organismos que evoluíram a partir de relações independentes. (ISA, 2003)

${ }^{20}$ A escala da própria monocultura enseja riscos ecológicos, inclusive pragas novas ou que crescem, e problemas de enfermidades como a ferrugem da soja, que aumentou drasticamente no Brasil (WWF, 2014, p. 64)

${ }^{21}$ Com efeito, os impactos ambientais decorrentes das monoculturas compreendem também o uso excessivo de agrotóxicos, afinal ocorre por um lado a simplificação biológica do agrossistema que passa a necessitar de fertilizantes, e por outro o aumento da população de insetos, fungos e agentes fitopatogênicos que se alimentam daquele tipo de planta.

${ }^{22}$ Como visto anteriormente o crescimento das monoculturas é simultâneo ao aumento no uso de insumos. Qualquer relação entre produção de grãos e monocultura só existe pelo uso de fertilizantes. Inclusive alguns estudos apontam que a quantidade de produção em monoculturas está em declínio mesmo com o aumento de fertilizantes, o que demonstra a deterioração e limitação ecológica das plantações dependentes de insumos

${ }^{23}$ Segundo Porto-Gonçalves (2006, p. 246), a relação entre produção de grãos e uso de fertilizantes caiu de 42 toneladas para 13 toneladas de grãos por cada tonelada de fertilizantes usada entre 1950 a 2000. Diante disso, conclui $\mathrm{o}$ autor que saltam à vista as limitações ecológicas desses agroecossistemas, na medida em que, sendo extremamente simplificados, são, por isso mesmo, dependentes de insumos externos para manter seu equilíbrio dinâmico.
} 
Talvez a única vantagem das monoculturas seja diminuição na necessidade de força de trabalho. A agricultura com intensa utilização de maquinários e insumos necessita cada vez menos de pessoas trabalhando. A pulverização de agrotóxicos por aviões e a colheita mecanizada com máquinas são exemplos de como o agronegócio está cada vez mais independente do trabalho humano. Desta forma, o processo produtivo do agronegócio gera concentração de terras e riqueza, e, consequentemente, o aumento da pobreza da população rural e pequenos agricultores. Isso significa sérias desvantagens sociais pelo desemprego e segregação social. Existe uma outra facilidade nas monoculturas: o uso de organismos geneticamente modificados, tão utilizados para a soja, que por si só trazem outros problemas ambientais, como se verá a seguir.

\subsection{OS ORGANISMOS GENETICAMENTE MODIFICADOS}

Os cultivos transgênicos expõem a natureza e pessoas a sérios riscos. As externalidades negativas são muitas: riscos à saúde; perda da diversidade genética na agricultura; perda da diversidade genética natural; poluição genética; surgimento de superpragas; extermínio de insetos benéficos para a agricultura; desaparecimento da vida microbiana no solo; impactos nos ecossistemas; controle das sementes por multinacionais; aumento de desemprego e exclusão social e; riscos à segurança alimentar ${ }^{24}$.

É verdade que inexistem conhecimentos científicos suficientes sobre tais impactos do uso de transgênicos no meio ambiente e na saúde. Essa falta de embasamento cientifico pelos defensores dos transgênicos é justificativa pela sua manutenção e liberação no meio ambiente. Entretanto, fatos recentes mostram que na prática algumas delas já estão acontecendo ${ }^{25}$.

Um dos efeitos mais evidentes é a perda da diversidade genética da agricultura pela poluição genética, uma vez que a utilização das plantas transgênicas em larga escala provocou a disseminação indesejada dos transgenes ${ }^{26}$, cultivos de variedades convencionais ou orgânicos estão sendo contaminados. A contaminação genética pelo pólen transgênico e consequente erosão

\footnotetext{
${ }^{24}$ Como efeitos secundários se vislumbra a negação do direito dos consumidores à informação dos riscos associados ao seu uso, assim como a inexistência de regulamentos técnicos para o uso seguro destes produtos, e até mesmo não assunção da responsabilidade pelos riscos dos transgênicos pelas empresas deste setor.

${ }^{25}$ O Ministério do Meio Ambiente afirma que outros riscos já foram comprovados como: as variedades transgênicas de soja e algodão resistentes a determinados herbicidas se mostraram mais frágeis aos ataques de outras pragas em relação às convencionais, bem como criação de super pragas; transferência dos transgenes para plantas daninhas, criando super daninhas e; contaminação de produtos naturais como o mel. (BRASIL, 2017c)

${ }^{26}$ Quanto à preocupação das plantas transgênicas transferirem seus genes para outras plantas e provocarem a perda da diversidade genética, há evidências de que o milho geneticamente modificado da empresa Novartis tenha contaminado por polinização um plantio de milho tradicional na Alemanha. Isso levou a Noruega, Áustria e Luxemburgo a proibir o seu cultivo devido a prováveis prejuízos à biodiversidade e à saúde humana. Ver mais em: http://www.portalsaofrancisco.com.br/culinaria/alimentos-transgenicos.
} 
da diversidade genética é um fato constatado preocupante ${ }^{27}$. Ainda não se sabem todos os efeitos dessa disseminação na biodiversidade, mas se evidenciou a eliminação de variedades e que o alastramento não é controlável ${ }^{28}$.

Outro efeito preocupante dos OGM's é a diminuição dos insetos em geral (não somente as pragas), bem como impactos negativos em organismos não alvo (abelhas, mariposas e predadores de insetos). Polinizadores, predadores e parasitoides de insetos são afetados pelas toxinas das plantas geneticamente modificadas de diferentes maneiras. Alguns se tornam resistentes e invertem a cadeia de predadores, outros perdem longevidade e fecundidade, enquanto demais são exterminados. (GARCIA, 2001)

Pelo aspecto social se observam duas consequências à contaminação dos OGM's. A primeira é o surgimento de conflitos entre agricultores e empresas, ou entre agricultores. A presença de organismos, mesmo que indesejável, gera a descaracterização de produções orgânicas ou de outras modalidades de soja, bem como deu margem para ações judiciais de apropriação indébita por parte dos detentores de transgenes. Vários agricultores foram vítimas de cobranças de propriedade intelectual, processados e multados por uma contaminação indesejada ${ }^{29}$. A segunda é que o cruzamento entre variedades acarreta prejuízos financeiros e biológicos pela falta de variedades, o produto transgênico se torna a única opção disponível e os agricultores ficam reféns das grandes empresas. Portanto, é possível afirmar que não há controle sobre a expansão dos transgênicos, não há controle sobre os efeitos da disseminação, não há previsibilidade de longo prazo em demais organismos nem a totalidade dos impactos socioeconômicos.

Por fim, cabe o destaque que os OGM's aumentaram a demanda por insumos químicos. A relação entre o cultivo de transgênicos e o aumento do uso de agrotóxicos é notória, uma vez que várias plantas geneticamente modificadas aprovadas para comercialização no Brasil sofreram alteração para receber agrotóxicos. (CARNEIRO, et.al, 2015, p. 113)

Se antes os agricultores regulavam o uso para não prejudicar as culturas, as plantas geneticamente modificadas possuem uma alta resistência aos herbicidas e o seu uso pode ser cada

\footnotetext{
${ }^{27}$ Uma estimativa do Ministério do Meio Ambiente informa que até meados de julho de 2005, foram comprovados 72 casos de contaminação de alimentos, rações animais, sementes, espécies nativas e selvagens por OGMs, e 11 casos de liberações ilegais de OGMs, atingindo 27 países. Foram, ainda, verificados 6 casos com efeitos agronômicos negativos. No total, tem-se o relato de 89 casos envolvendo organismos geneticamente modificados. Hoje esses números já devem ser muito maiores.

${ }^{28}$ Um exemplo é a contaminação da soja orgânica no Rio Grande do Sul. Esse tipo de contaminação pode ser tanto por cruzamento como pela mistura de sementes. Num estudo feito pela Union of Concerned Scientists em 2004, foi constatado que, pelos menos $50 \%$ das variedades convencionais de soja, milho e canola, vendidas para semeadura, já estão contaminadas pelos transgenes. (BRASIL, 2017b)

${ }^{29}$ Ler mais no texto do Greenpeace: http://www.greenpeace.org/brasil/PageFiles/4590/contaminacao_royalties.pdf
} 
vez mais intenso. De fato, as plantas transgênicas resistentes aos herbicidas aumentam o grau de dependência dos agricultores aos agrotóxicos.

Por outro lado, mesmo com o uso intensivo de agrotóxicos, como o glifosato, já surgiram pragas resistentes que obrigam os agricultores a elevar a quantidade do veneno ou mudar de insumo. Trata-se de uma vinculação entre transgênicos e agrotóxicos como o resultado do modelo tecnológico hegemônico que considera o agrotóxico o único caminho para aumentar a produtividade agrícola (CARNEIRO, et.al, 2015, p. 113). Inclusive, a venda de sementes transgênicas é casada com a dos agrotóxicos, produzidos, em geral, pelas mesmas indústrias. Meia dúzia de empresas dominam o mercado de sementes geneticamente modificadas e de agrotóxicos conjuntamente. (CARNEIRO, et.al, 2015, p. 113)

\subsection{OS INSUMOS QUIMICOS - FERTILIZANTES E AGROTÓXICOS}

Por último, cabe revelar as externalidades negativas dos insumos químicos nos cultivos. A questão é que os modelos agrícolas com uso de monoculturas e simplificação do cultivo somente se sustentam à custa do uso de insumos químicos. Diante do exposto, a agricultura moderna requer o uso intensivo de fertilizantes, pesticidas e herbicidas, o que se traduz em uma das principais ameaças contra o meio ambiente e saúde humana. Os efeitos dos insumos independem do tamanho da unidade agrícola, o que acontece é um agravo pelo uso em mais áreas e/ou uso intensivo. (WWF, 2014, p. 63)

Falar de agrotóxicos é falar de contaminação de solo e água, bem como demais implicações ambientais e sociais. De acordo com o Ministério do Meio Ambiente, o comportamento dos agrotóxicos uma vez liberados é bastante complexo. Eles atingem o solo e as águas, principalmente devido aos ventos e à água das chuvas, que promovem a deriva, a lavagem das folhas tratadas, a lixiviação e a erosão ${ }^{30}$.

A contaminação de coleções de água superficiais e subterrâneas tem um potencial extremamente poluente, pois se, por exemplo, o local onde for aplicado o agrotóxico for próximo a um manancial hídrico que abasteça uma cidade, a qualidade dessa água captada também deverá estar comprometida. No que diz respeito à contaminação no solo, o acúmulo dos agrotóxicos pode

\footnotetext{
${ }^{30}$ Essas substancias liberadas sofrem deslocamentos físicos e transformações químicas e biológicas, que podem modificar suas propriedades e formar subprodutos com propriedades absolutamente distintas do produto inicial e cujos danos à saúde ou ao meio ambiente também são diferenciados (BRASIL, 2017c). A dispersão no ambiente causa um desequilíbrio ecológico na interação entre os processos físicos e biológicos, na própria interação entre espécies. Os produtos se acumulam no meio ambiente e percorrem longos caminhos.
} 
fragilizar e desencadear absorção de elementos minerais, principalmente em solos desnudos, concorrendo para a redução do grau de fertilidade do mesmo. (BRASIL, 2017c) No Mato Grosso, palco principal do agronegócio brasileiro, das monoculturas, das plantas transgênicas e de uso intensivo de agrotóxicos, viu-se os efeitos da pulverização aérea com contaminação das águas e do leite materno, assim como contaminação de anfíbios por exposição ambiental aos agrotóxicos. (CARNEIRO, et.al, 2015, p.55)

É possível dizer que não existe sustentabilidade quanto ao uso dos agrotóxicos, pois sua necessidade aumenta cada vez conforme mais deteriora o meio do cultivo, é um ciclo vicioso. Por pode-se dar a característica do agronegócio brasileiro de monocultura químico-dependente ${ }^{31}$.

Outro efeito grave é a extinção da biodiversidade, plantas e animais.

Os agrotóxicos além de matarem plantas, atuam sobre a vida macrobiótica e animal. Além de erradicarem as pragas, também eliminariam seus inimigos naturais, ou seja, seus predadores e competidores. Alguns tipos de agrotóxicos - como os organoclorados, já amplamente proibidos, porém com passivo ambiental decorrente de sua elevada persistência - se acumulam ao longo da cadeia alimentar por meio da biomagnificação, a presa contaminando o predador $^{32}$. (BRASIL, 2017c)

No Rio Grande do Sul os apicultores demonstram uma mortalidade crescente das abelhas, soma-se que 250 mil desapareceram em 2015 no estado ${ }^{33}$. Esse fato causa grande impacto no estado, o maior produtor de mel do brasil. A causa apontada pelos especialistas é o uso de agrotóxicos, aliado ao desmatamento ${ }^{34} .35$

\footnotetext{
${ }^{31}$ Mostra-se o crescente consumo de agrotóxicos e fertilizantes químicos pela agricultura brasileira, proporcional ao aumento das monoculturas, cada vez mais dependentes dos insumos químicos. Como visto no primeiro tópico, as maiores concentrações de utilização de agrotóxicos coincidem com as regiões de maior intensidade de monoculturas de soja, milho, cana, cítricos, algodão e arroz.

${ }^{32}$ Animais não alvos considerados benéficos também são contaminados, como anfíbios e polinizadores. Uma pesquisa no Mato Grosso demonstrou que a contaminação das águas gerou a contaminação de anfíbios por exposição ambiental aos agrotóxicos. (CARNEIRO, et.al, 2015, p.55)

${ }^{33}$ Segundo a reportagem "No Estado a morte de abelhas tornou-se generalizada, principalmente em áreas com uso intensivo de agrotóxicos", afirma o coordenador da Câmara Setorial de Apicultura e Meliponicultura da Secretaria Estadual da Agricultura (Casam), Nadilson Ferreira. "O problema atinge maiores proporções nas regiões da Depressão Central, Missões, Alto Uruguai e parte da Campanha. Os agrotóxicos estão acelerando a perda de biodiversidade e contribuindo para o extermínio das populações de abelhas", completa. (NENÊ, 2017)

${ }^{34}$ As mortes começaram a ocorrer de forma anormal, sem nenhuma doença ou desnutrição. A diferença começou a ocorrer por volta de 2014 com morte repentina de abelhas, ainda é preocupante que todas as espécies de abelha são atingidas. (NENÊ, 2017)

Em 2015 foi criado um grupo de trabalho sobre a mortandade das abelhas, o grupo concluiu que houve uma redução de $40 \%$ da produção de mel, e onde é mais atingido são regiçoes com maior produção de cultivos anuais de soja, milho e arroz. Mas não é a proximidade o problema para as mortes, e sim os produtos químicos utilizados. (NENÊ, 2017)

35 "Já vi um enxame e no outro dia, depois que passaram veneno por perto, as abelhas estavam todas mortas. E a caixa fica imunizada, porque novos enxames na mesma caixa morrem também. Disseram que é um veneno que se um só inseto leva para a colmeia, contamina todas as outras". (NENÊ, 2017)
} 
O relatório do grupo reforça como principal causa "O uso em larga escala no Brasil de agrotóxicos com efeitos nocivos às abelhas, em especial aqueles do grupo dos Neonicotinóides (Clotianidina, Imidacloprid, Tiametoxam) e Fipronil”36.Vários agricultores dependem da renda da apicultura, o prejuízo é enorme. Os apicultores ainda informam o temos que o mel gaúcho passe a sofrer restrições pela contaminação com os venenos. (NENÊ, 2017)

Outro problema para os insetos que conhece pelo uso de agrotóxicos é a criação de pragas resistentes. Acrescenta-se o fato de que alguns indivíduos são mais resistentes, o que faz com que, na maior parte das vezes, as pragas não sejam completamente dizimadas, restando indivíduos com genótipo mais forte. O cruzamento desses indivíduos, em adição a uma menor competição por alimento, espaço e abrigo, promove aumentos substanciais na população, fazendo com que a praga volte mais resistente e em níveis populacionais maiores do que antes da aplicação química ${ }^{37}$.

Qualquer que seja o caminho do agrotóxico no meio ambiente, invariavelmente o homem é seu potencial receptor também, o aumento no uso de agrotóxicos aumenta a vulnerabilidade humana de exposição.

Existem casos concretos de contaminação por agrotóxicos da população, principalmente trabalhadores e moradores de áreas pulverizadas, mas também em populações atingidas pelos corpos hídricos e alimentos contaminados. Trata-se de uma violência contra à saúde e dignidade das pessoas. (CARNEIRO, et.al, 2015, p. 177)

O Estudo Mapa da Contaminação por Agrotóxico no Brasil, realizado por pesquisadoras da Universidade de São Paulo apresentou dados como: Intoxicação alimentar, câncer, problemas neurológicos e até genéticos. A pesquisa só contabilizou sintomas ligados direta e imediatamente aos agrotóxicos ${ }^{38}$. (SPITZCOYSKY, 2016)

No estado do Mato Grosso se verificou efeitos em humanos da incidência dos agrotóxicos, como intoxicações aguras, más-formações e agravos respiratórios, que aumentaram e entre $40 \%$ e $102 \%$ nos últimos dez anos, com linha de tendência com 50\% acima da incidência anual estadual destes anos. Além disso, os indicadores e incidência desses agravos estavam diretamente

\footnotetext{
${ }^{36}$ Esses, especificamente, são os que têm ação fulminante sobre as abelhas, salienta Sanderlei. Eles causam a morte das polinizadoras até mesmo quando são usados no tratamento das sementes porque são sistêmicos, ou seja, entram na seiva das plantas e contaminam o pólen e néctar de suas flores, que são visitadas pelas abelhas quando acontece a floração. (NENÊ, 2017)

${ }^{37}$ Acrescenta-se o fato do aumento de resistência por parte das pragas, que passam a tolerar doses que antes matavam quase a totalidade de seus progenitores (SOARES, 2010, p. 8). Por exemplo, entre 1940 e 1984 as perdas das culturas por ataques de insetos, nos EUA, aumentaram de $7 \%$ para $13 \%$, enquanto o uso de pesticidas aumentou 12 vezes. (SOARES, 2010, p. 8)

${ }^{38}$ A obra final Geografia sobre o Uso de Agrotóxicos no Brasil deve ser lançada em breve. (SPITZCOYSKY, 2016)
} 
correlacionados com a produção agrícola temporária (soja, milho e algodão) e a exposição aos agrotóxicos usados nessas lavouras. (CARNEIRO, et.al, 2015, p. 155)

Inclusive, a contaminação de peixes, crustáceos, moluscos e outros animais representa uma fonte potencial de contaminação humana, cujos riscos podem ser ampliados a todos os consumidores desses animais como fonte de alimento.

Quando se fala de externalidades negativas aos humanos, fala-se também da estrutura produtiva subordinada ao modelo conservador e do acesso das assistências públicas de crédito e pesquisas $^{39}$. (CARNEIRO, et.al, 2015, p. 22)

Esses dados revelam ainda mais da complexidade e das injustiças socioambientais da questão agrária no Brasil, pois indicam que as populações mais pobres, que vivem nas menores propriedades, têm graves limitações de acesso a políticas sociais, também têm dificuldade em acessar a assistência técnica. O Dossiê Abrasco (CARNEIRO, et.al, 2015) denuncia que essa situação conta com o apoio dos Estado, pelo financiamento do agronegócio, o que caracteriza violações dos direitos da população do território.

\section{A JUSTIÇA AMBIENTAL E O AGRONEGÓCIO}

Para o agricultor, sob o ponto de vista estritamente econômico, vale a pena plantar sistemas de monocultura que utilizam menos trabalhadores, utilizar OGM's resistentes e comprar e utilizar o agrotóxico quando seu custo se encontra menor do que o benefício esperado na produção. Os custos das sementes e dos agrotóxicos são repassados ao consumidor no preço final do alimento, mas se restringem ao custo da compra do agricultor.

Mas os danos ambientais e à saúde humana provenientes do uso desses elementos não são carregados no processo produtivo, ou seja, nem as sementes vendidas pelas corporações e nem os preços dos agrotóxicos refletem esses custos, tampouco os preços dos produtos agrícolas colocados à venda no mercado.

É um custo absorvido por toda a sociedade sob as mais diferentes maneiras, mas que não é diretamente percebido por essa. É um custo externalizado nas planilhas do Ministério da Saúde ao se repassar verba para o atendimento médico-hospitalar no Sistema Único de Saúde, nas despesas do Ministério da Previdência Social para concessão dos benefícios, do Ministério do Meio

\footnotetext{
${ }^{39}$ Neste sentido, o auxílio do poder público à agricultura familiar e pequenas propriedades também estimulava a produção com agrotóxicos e plantio de monoculturas, processo resultante da modernização da agricultura nas décadas de 1960 e 1970. Isso porque o crédito rural e a assistência técnica e da pesquisa só eram disponíveis para esse modelo, inclusive induziam ao uso de insumos químicos. (CARNEIRO, et.al, 2015, p. 22)
} 
Ambiente na luta de garantir o equilíbrio ecológico e a manutenção das espécies, dentre outros gastos governamentais ou não.

A realidade atual é o Leff explica como o enfoque mercadológico, que gera uma retotalização do mundo sob o valor unidimensional do mercado, superexplorando a natureza, homogeneizando culturas, subjugando saberes e degradando a qualidade de vida das maiorias (2001, p. 40).

E aqui se levanta a teoria da Justiça Ambiental. O movimento tem suas origens nos movimentos por direitos civis nos anos 1960 aliada aos movimentos sindicais dos trabalhadores agrícolas e defesa do meio ambiente para a saúde humana (ALIER, 2007, p. 231). Mas realmente se formou por grupos populares de base nos Estados Unidos nos anos $1980^{40}$, em lutas de caráter social, territorial ambiental e de direitos civis. Certas analises apontavam a vulnerabilidade da população e dessas ambientais desigualmente distribuídos (ACSELRAD; MELLO; BEZERRA, 2015, p. 18).

Depois de diversos estudos e manifestos, o movimento da justiça ambiental consolidou-se como "[...] uma rede multicultural e multirracial nacional, e em seguida internacional, articulando entidades de direitos civis, grupos comunitários, organizações de trabalhadores, igrejas e intelectuais" para fundir direitos civis e preocupações ambientais em uma mesma agenda, reconhecendo o caráter indissociável de ambiente e sociedade, as relações entre risco ambiental, pobreza e etnicidade ${ }^{41}$.

Foi na década de 90 que começa a ocorrer a internacionalização do movimento por justiça ambiental. Seu principal marco foi o "Memorando Summers" veiculado, em 1991, pelo Banco Mundial. Este, que era para ser de circulação restrita, acabou vazando para o público (através, principalmente, da publicação Let them eat pollution realizada pela revista The Economist), causando repercussões negativas à instituição ${ }^{42}$. A partir disso o movimento de justiça ambiental procurou se internacionalizar para construir uma resistência global às dimensões mundiais da reestruturação espacial da poluição. A bandeira da justiça ambiental reconhece o perfil cada vez

\footnotetext{
${ }^{40} \mathrm{O}$ marco para a Justiça ambiental é a luta em Afton, no condado de Warren no estado da Carolina do Norte em 1982, que combateu a instalação de um depósito tóxico perto da localidade, que geraria a contaminação da rede de abastecimento de água da cidade. Esse fato que elevou a justiça ambienta à condição de questão central na luta pelos direitos civis (ACSELRAD; MELLO; BEZERRA, 2015, p. 20)

${ }^{41}$ O documento"17 Princípios da Justiça Ambiental" de 1991 estabelece uma agenda nacional para redesenhar a política ambiental dos EUA de modo a incorporar a pauta das minorias, comunidades ameríndias, latinas, afroamericanas e asio-americanas, tentando mudar o eixo de gravidade da atividade ambientalista. (ACSELRAD; MELLO; BEZERRA, 2015, p. 20)

${ }^{42}$ Nele, o economista chefe do Banco Mundial, Lawrence Summers (daí o nome do informe), defendia a "migração de indústrias poluentes para os países menos desenvolvidos", a partir de três motivos: da lógica econômica do custobenefício dessas movimentações, da subpoluição existente naquelas localidades e da preocupação "estética" e saudável das nações "ricas" com o meio ambiente. (ACSELRAD; MELLO; BEZERRA, 2015, p. 07-08).
} 
mais globalizado dos processos de sobreposição dos riscos sociais e ambientais ${ }^{43}$. (ACSELRAD; MELLO; BEZERRA, 2015, p. 36)

\subsection{AS EXTERNALIDADES NEGATIVAS SOB A ÓTICA DA JUSTIÇA AMBIENTAL}

Justiça ambiental é "[...] a condição de existência social configurada através do tratamento justo e do envolvimento significativo de todas as pessoas, independentemente de sua raça, cor ou renda nhoque diz respeito à elaboração, desenvolvimento, implementação e aplicação de políticas, leis e regulações ambientais.” (ACSELRAD; MELLO; BEZERRA, 2015, p. 16). O tratamento justo significa que nenhum grupo de pessoas deva suportar uma parcela desproporcional das consequências ambientais negativas dos empreendimentos.

Essa teoria hoje promove o deslocamento do debate ambiental para o patamar de justiça social, convertendo a luta para "nenhum quintal" sofrer efeitos de negativos e ampliando o círculo de pessoas implicadas na política ambiental. (ALIER, 2007, p. 235) Poluição tóxica para ninguém é um dos lemas do movimento, uma luta de caráter solidário, que busca colocar na pauta publica a denúncia da logica sociopolítica promotora de desigualdades ambientais com a demanda de evitar empreendimentos ambientalmente perversos, e que qualquer tipo de população politicamente mais fraca sofra suas consequências. (ACSELRAD; MELLO; BEZERRA, 2015 p. 27)

Isso significa contestar o modelo de desenvolvimento que configura um padrão sociopolítico que carrega malefícios à saúde e ao bem-estar as populações destituídas de recursos financeiros ou políticos, no sentido que injustiça ambiental é a "[...] a imposição desproporcional dos riscos ambientais às populações menos dotadas de recursos financeiros, políticos e informacionais". (ACSELRAD; MELLO; BEZERRA, 2015, p. 09).

Dentre as campanhas da justiça ambiental se encontram as lutas contra as monoculturas, pelo banimento de substancias tóxicas, contra a violência no campo (de indígenas, quilombolas, populações tradicionais) vitimas da expansão do agronegócio, contra o crescimento econômico a qualquer custo. (ACSELRAD; MELLO; BEZERRA, 2015, p. 45)

\footnotetext{
${ }^{43}$ Em um contexto global, se observa que os países industrializados dependem de importações provenientes do sul para atender parcela crescente e cada vez maior das suas demandas por matérias-primas e bens de consumo. (ALIER, 2007, p. 34). Causando uma pressão imensa para os países atenderem essa demanda independente dos custos aos seus biomas e população. Inclusive, o comércio que favorece commodities manufaturados reforça a vulnerabilidade econômica dos países como o Brasil. (GONZALEZ, 2015, p. 161)
} 
São vastos os problemas expressivos de cunho ambiental e social resultantes do capitalismo agrário. Nesse caso, na presença desses custos externos ou externalidades, percebe-se que o benefício privado não se reflete em benefício social, ou melhor, que a estimativa de um benefício socialmente desejável é obtida pela maximização da função de bem estar social e não através da função exclusivamente privada de exportação de commodities com acumulação individual de riqueza. Isso pode ser verificado na migração e mobilidade das monoculturas no mundo e dentro do próprio país, como visto hoje o cultivo de soja está se deslocando para o norte do país, se afastando das zonas mais desenvolvidas. Outro aspecto é a utilização de transgênicos e agrotóxicos no Brasil que em outros países são proibidos.

Desta forma, o que ocorre com as monoculturas para commodities no Brasil é um caso de injustiça ambiental, uma vez que essa teoria informa que a população é atingida pelos impactos ambientais dos grandes projetos de desenvolvimento pela expansão da atividade econômica para geração de riqueza individual. A monocultura provoca grande desestabilização (se não impossibilidade) das demais atividades nas terras por diversos tipos de externalidades que atingem os ecossistemas, os animais e os humanos.

Os espaços produtivos privados transmitem seus efeitos nocivos para o meio ambiente comum, praticas ambientalmente danosas integradas aos grandes circuitos de mercado, usufruindo relações privilegiadas com o poder publico, contando com toda a assistência para sua instalação e manutenção. (ACSELRAD; MELLO; BEZERRA, 2015, p. 74)

São problemas expressivos de cunho ambiental e social resultantes do capitalismo agrário. Nesse caso, na presença desses custos externos ou externalidades, percebe-se que o benefício privado não se reflete em benefício social, ou melhor, que a estimativa de um benefício socialmente desejável é obtida pela maximização da função de bem estar social e não através da função exclusivamente privada de exportação de commodities com acumulação individual de riqueza. A ideia de Justiça, ao contrário, remete a uma distribuição equânime de partes e à diferenciação qualitativa do meio ambiente.

Como explicam Acselrad, Mello e Bezerra (2015, p. 75) o agravante em termos de justiça ambiental é que essas grandes produções de monocultura altamente mecanizadas gerem pouquíssimos empregos em relação ao seu consumo de recursos naturais e/ou degradação do meio ambiente em comum. Enquanto praticas socioeconômicas artesanais ou pequenas produções são responsáveis pela subsistência de um número expressivo de pessoas ${ }^{44}$.

\footnotetext{
${ }^{44}$ Inclusive está na pauta da justiça ambiental transformar o modelo de desenvolvimento considerando uma transição justa, de modo que a luta contra as externalidades negativas não destrua o emprego dos trabalhadores ou transferir os poluentes para outras populações vulneráveis. (ACSELRAD; MELLO; BEZERRA, 2015, p. 29)
}

Rev. de Direito Agrário e Agroambiental | e-ISSN: 2526-0081| Maranhão | v. 3 | n. 2 | p. 1 - 25 | Jul/Dez. 2017 
O discurso dos movimentos por justiça ambiental evidencia o caráter fortemente desigual da apropriação das partes do meio ambiente e dos seus recursos, assim como quem irá sofrer com as externalidades negativas. Pensar justiça ambiental é pensar o que se produz, como se produz e para quem se produz. (ACSELRAD; MELLO; BEZERRA, 2015, p. 75) Mas também apontar a concentração dos benefícios do desenvolvimento nas mãos de poucos, bem como que os mais pobres são os mais atingidos nessas relações por não possuírem modos de se recuperarem das externalidades.

O movimento da justiça ambiental veio para criticar que não existe distribuição democrática dos riscos ambientais. A justiça ambiental critica o raciocínio que essas externalidades atingem toda a sociedade igualmente. Na verdade, é possível constatar que "[...] sobre os mais pobres e os grupos étnicos desprovidos de poder recai, desproporcionalmente, a maior parte dos riscos ambientais socialmente induzidos" (ALIER, 2007, p. 12), como nos processos de plantio ou recepção de resíduos, assim como deterioração dos recursos naturais dos quais tiram seus sustentos.

É preciso ressaltar na teoria da justiça ambiental o interesse material pelo meio ambiente como fonte de condição para a subsistência, não precisamos nem falar das demais espécies e futuras gerações dos humanos (que devem sim ser levados em conta), mas pelos humanos de hoje que já estão sofrendo com a deterioração ambiental, já que os pobres são a ampla maioria da população do país. (ALIER, 2007, p. 35)

Assim, a concepção monocultural exportadora dominante é questionada pelo movimento de justiça ambiental cuja a racionalidade do movimento ambiental busca reapropriação social da natureza, caracterizado pela diversidade de seus atores e, principalmente, de suas reivindicações: a defesa dos direitos a ambientes cuturalmente específicos (comunidades tradicionais) situadas na fronteira de expansão das atividades de mercado; defesa dos direitos a uma proteção ambiental equinanime contra a segregação socioterritorial e de desigualdade ambiental promovida pelo mercado e; defesa dos direitos de acesso equânime aos recursos ambientais contra concentração de terras, águas e do solo seguro contra os interesses econômicos. Bem como a defesa dos direitos da populações futuras, vulneráveis das ações destrutivas. (ACSELRAD; MELLO; BEZERRA, 2015, p. 146) 


\section{CONCLUSÃO}

Ao guiar-se pela lógica da extração de lucro no curto prazo, o agronegócio se reproduz por meio de economias de escala que induzem a ocupação dos territórios rurais com extensas monoculturas e criatórios industrializados. Trata-se de monoculturas químico-dependentes, em que o aumento das monoculturas coincide com a intensidade no uso de agrotóxicos.

Diretamente desse modo de produção de commodities para exportação derivam externalidades negativas, que envolvem desmatamento, monoculturas, organismos geneticamente modificados, utilização de insumos químicos (agrotóxicos, fertilizantes químicos). Os impactos ambientais e sociais de tais processos são extensos e precisam ser considerados na continuidade da sociedade e dos seus modos de produção.

É importante destacar que as externalidades negativas da expansão agrícola, das monoculturas, dos OGM's e dos agrotóxicos não podem ser vistos como fatos isolados em um sistema econômico, ou mesmo ecológico. É uma realidade de composta por uma junção de fatores, são diversos elementos e impactos ambientais e sociais. Neste sentido, repensar o papel do direito sob a ótica da justiça é um caminho para considerar a complexidade da questão e problemática que se coloca.

Por isso, a questão da justiça ambiental surge, na busca da sustentabilidade, nos planos nacional e internacional, fundada na consciência da possibilidade do esgotamento dos recursos naturais, dos problemas das externalidades e do direito do ser humano ao meio ambiente ecologicamente equilibrado para uso pelas gerações atuais e futuras.

Nessa conjuntura, é preciso uma luta em prol da justiça ambiental, que preza pela utilização dos recursos do meio ambiente dentro de certos limites, em prol da sociedade e com responsabilidade ambiental para não deteriorar o direito fundamental ao meio ambiente ecologicamente equilibrado, de uso comum do povo e essencial à sadia qualidade de vida. Bem como o uso dos recursos naturais merece distribuição de forma igualitária ao homem em relação aos ganhos e perdas ambientais.

O que se precisa é consolidar a difusão da justiça ambiental no combate à desigualdade para a proteção do meio ambiente com a consciência que o social e o natural precisam ser discutidos em conjunto em prol do bem-estar das pessoas e do equilibro natural. Cabe concluir, que a justiça ambiental busca fazer do ambiente um espaço de construção da justiça e não apenas de realização utilitária do mercado. 


\section{REFERÊNCIAS}

ACSELRAD, Henri; Mello, Cecilia C.A. e BEZERRA, Gustavo N. O que é justiça ambiental. São Paulo: Saraiva, 2015.

ALIER, Joan Martínez. O ecologismo dos pobres: conflitos ambientais e linguagem de valoração. Tradução de Maurício Waldman. São Paulo: Contexto, 2007.

ARAÚJO, Laís S. Transgênicos já chegam a 93\% da área plantada com soja, milho e algodão. Brasil de Fato, São Paulo, 01 set. 2016.

BRASIL, Ministerio do Meio Ambiente - MMA. Impactos sobre a Biodiversidade. Disponível em: <http://www.mma.gov.br/biodiversidade/biodiversidade-global/impactos>. Acesso em: 10 de ago. 2017.

BRASIL, Ministerio do Meio Ambiente - MMA. Riscos. Disponível em <http://www.mma.gov.br/informma/item/7511-riscos>. Acesso em: 05 de ago. 2017b.

BRASIL, Ministério do Meio Ambiente - MMA. Segurança Química. Disponível em: <http://www.mma.gov.br/seguranca-quimica/agrotoxicos>. Acesso em 2 de ago. 2017c.

BRASIL. Ministério da Agricultura, Pecuária e Abastecimento - MAPA. Plano Agrícola e Pecuário 2016-2017 / Ministério da Agricultura, Pecuária e Abastecimento. Secretaria de Política Agrícola. - Brasília: Mapa/SPA, 2016.

CARNEIRO, Fernando Ferreira; AUGUSTO, Lia Giraldo da Silva; RIGOTTO, Raquel Maria.et.al (Org.) Dossiê ABRASCO: um alerta sobre os impactos dos agrotóxicos na saúde. Rio de Janeiro: EPSJV; São Paulo: Expressão Popular, 2015.

Companhia Nacional de Abastecimento - CONAB. Acompanhamento safra brasileira de grãos, v. 9 Safra 2015/16 - Nono levantamento, Brasília, p. 1-178, junho 2016. Disponível em: <http://www.conab.gov.br/OlalaCMS/uploads/arquivos/16_06_09_09_00_00_boletim_graos_ju nho_2016_-_final.pdf $>$. Acesso em 01 de ago. 2017.

Confederação da Agricultura e Pecuária do Brasil - CNA. 06 de dez. 2016. Agropecuária supera obstáculos e segue liderando a economia brasileira em 2016. Disponível em: $<$ http://www.cnabrasil.org.br/noticias/agropecuaria-supera-obstaculos-e-segue-liderandoeconomia-brasileira-em-2016>. Acesso em: 05 de ago. 2017.

Empresa Brasileira de Pesquisa Agropecuária - EMBRAPA. Soja em números. Disponível em: <https://www.embrapa.br/web/portal/soja/cultivos/soja1/dados-economicos>. Acesso em $01 \mathrm{de}$ ago. 2017.

GONZALEZ, Carmen G. Environmental Justice, Human Rights, and the Global South. 13 Santa $\begin{array}{llllll}\text { Clara } & \text { J. } & \text { Int'l } & \text { L. } & 151 & \text { (2015). Disponível }\end{array}$ em:<http://digitalcommons.law.scu.edu/cgi/viewcontent.cgi $?$ article=1183\&context=scujil $>$. Acesso em: 15 de ago. 2017. 
GARCIA, Maria Alice. Alimentos Transgênicos: riscos e questões éticas. Revista de Agricultura, Piracicaba, V. 76, fasc. 3. 2001. Disponível em: <http://aspta.org.br/campanha/alimentostransgenicos-riscos-e-questoes-eticas-por-maria-alice-garcia/>. Acesso em: 05 de ago. 2017.

GIOVANAZ, Daniel P. O pampa virou areia: agronegócio intensifica processos de erosão no bioma gaúcho. Brasil de Fato, São Paulo, 24 de jan. 2017. Disponível em: $<$ https://www.brasildefato.com.br/2017/01/24/o-pampa-virou-areia-agronegocio-intensificaprocessos-de-erosao-no-bioma-gaucho/>. Acesso em: 03 de ago. 2017.

Instituto Socioambiental - ISA. O Xingu na mira da soja. Out. 2003.Disponível em: <https://siteantigo.socioambiental.org/esp/soja/4.shtm>. Acesso em 01 de ago. 2017.

Instituto Brasileiro de Geografia e Estatística - IBGE. Indicadores de desenvolvimento sustentável: Brasil. Coordenação de Recursos Naturais e Estudos Ambientais [e] Coordenação de Geografia. - Rio de Janeiro: IBGE, 2015.

Instituto Brasileiro de Geografia e Estatística - IBGE. Resultados da Produção Agrícola Municipal 2015. Coordenação de Agropecuária, 23 de set. 2016. Disponível em: <http://www.ibge.gov.br/home/presidencia/noticias/imprensa/ppts/000000274221091120162102 23405721.pdf>. Acesso em 01 de ago. 2017.

Instituto Brasileiro de Geografia e Estatística - IBGE. Indicadores IBGE Estatística da Produção Agrícola fevereiro de 2017.2 Disponíveis em: <ftp://ftp.ibge.gov.br/Producao_Agricola/Fasciculo_Indicadores_IBGE/estProdAgr_201702.pdf $>$. Acesso em 01 de ago. 2017.

Empresa Brasileira de Pesquisa Agropecuária - EMBRAPA. História da soja. Disponível em: <https://www.embrapa.br/soja/cultivos/soja1/historia>. Acesso em: 10 de ago. 2017.

LONDRES, Flavia. Transgênicos no Brasil: as verdadeiras consequências. Disponível em: <http://www.unicamp.br/fea/ortega/agenda21/candeia.htm>. Acesso em 03 de ago. 2017.

NENÊ, Ulisses. Agrotóxicos dizima comunidade de abelhas no Rio Grande do Sul. Brasil de Fato, São Paulo, 28 jul. 2017. EcoAgência. Disponível em: <https://www.brasildefato.com.br/2017/07/28/agrotoxicos-dizima-comunidade-de-abelhas-norio-grande-do-sul/>. Acesso em: 05 de ago. 2017.

PLATA. L. E. A. Mercado de terra no Brasil: Gênese, determinação de seus preços e políticas. Tese (Doutorado em Economia) - Instituto de Economia UNICAMP, 2001.

SOARES, Wagner Lopes. Uso dos agrotóxicos e seus impactos à saúde e ao ambiente: uma avaliação integrada entre a economia, a saúde pública, a ecologia e a agricultura. Tese (Doutorado em Ciências na área de Saúde Pública e Meio Ambiente - FIOCRUZ, 2010.

PORTO-GONÇALVES, Carlos Walter. A globalização da natureza e a natureza da globalização. Rio de Janeiro: Civilização Brasileira, 2006.

SCHMITZ, Arno Paulo; KAMMER, Eliana Maria. Sistemas de produção e custos na produção de soja orgânica, convencional e transgênica. Jul. 2006. Disponível em 
<https://www.researchgate.net/publication/228642123_Sistemas_de_producao_e_custos_na_pro ducao_de_soja_organica_convencional_e_transgenica>. Acesso em: 05 de ago. 2017.

SPITZCOYSKY, Débora. Mapa da contaminação por agrotóxico no Brasil revela regiões onde pessoas estão mais expostas. 25 jul. 2016. Disponível em: $<$ http://thegreenestpost.bol.uol.com.br/mapa-da-contaminacao-por-agrotoxico-no-brasil-revelaregioes-onde-pessoas-estao-mais-expostas/> . Acesso em: 12 de ago. 2017.

WALKER, Robert; DEFRIES, Ruth; VERA-DIAZ, Maria Del Carmem. et. al. A Expansão da Agricultura Intensiva e Pecuária na Amazônia Brasileira. Disponível em: <https://daac.ornl.gov/LBA/lbaconferencia/amazonia_global_change/5_A\%20Expansao_Agricul tura_Walker.pdf >. Acesso em: 05 de ago. 2017.

World Wide Fund for Nature - WWF. The growth of Soy: Impacts and Solutions. (O crescimento da soja: impactos e soluções). Gland: WWF, 2014. Disponível em: <http://d3nehc6yl9qzo4.cloudfront.net/downloads/wwf_relatorio_soja_port.pdf>. Acesso em: 05 de ago. 2017. 